Article

\title{
Towards Slow-Moving Landslide Monitoring by Integrating Multi-Sensor InSAR Time Series Datasets: The Zhouqu Case Study, China
}

\author{
Qian Sun ${ }^{1}$, Jun $\mathrm{Hu}^{2, *}$, Lei Zhang ${ }^{3}$ and Xiaoli Ding ${ }^{3}$ \\ 1 College of Resources and Environmental Science, Hunan Normal University, Changsha 410081, China; \\ sunqian200241@aliyun.com \\ 2 School of Geosciences and Info-Physics, Central South University, Changsha 410083, China \\ 3 Department of Land Surveying and Geo-Informatics, The Hong Kong Polytechnic University, \\ Hong Kong 999077, China; lslzhang@polyu.edu.hk (L.Z.); lsxlding@polyu.edu.hk (X.D.) \\ * Correspondence: csuhujun@csu.edu.cn; Tel.: +86-731-8883-0573
}

Academic Editors: Zhong Lu, Xiaofeng Li and Prasad S. Thenkabail

Received: 31 August 2016; Accepted: 28 October 2016; Published: 2 November 2016

\begin{abstract}
Although the past few decades have witnessed the great development of Synthetic Aperture Radar Interferometry (InSAR) technology in the monitoring of landslides, such applications are limited by geometric distortions and ambiguity of 1D Line-Of-Sight (LOS) measurements, both of which are the fundamental weakness of InSAR. Integration of multi-sensor InSAR datasets has recently shown its great potential in breaking through the two limits. In this study, 16 ascending images from the Advanced Land Observing Satellite (ALOS) and 18 descending images from the Environmental Satellite (ENVISAT) have been integrated to characterize and to detect the slow-moving landslides in Zhouqu, China between 2008 and 2010. Geometric distortions are first mapped by using the imaging geometric parameters of the used SAR data and public Digital Elevation Model (DEM) data of Zhouqu, which allow the determination of the most appropriate data assembly for a particular slope. Subsequently, deformation rates along respective LOS directions of ALOS ascending and ENVISAT descending tracks are estimated by conducting InSAR time series analysis with a Temporarily Coherent Point (TCP)-InSAR algorithm. As indicated by the geometric distortion results, 3D deformation rates of the Xieliupo slope at the east bank of the Pai-lung River are finally reconstructed by joint exploiting of the LOS deformation rates from cross-heading datasets based on the surface-parallel flow assumption. It is revealed that the synergistic results of ALOS and ENVISAT datasets provide a more comprehensive understanding and monitoring of the slow-moving landslides in Zhouqu.
\end{abstract}

Keywords: landslides; InSAR; Zhouqu; multi-sensor; geometric distortion; 3D deformations

\section{Introduction}

Characterized by high frequency, random distribution, strong concealment and complicated causes, landslides have become one of the most common and serious geo-hazards in the world. Slow-moving landslide deformation at the level of millimeter or centimeter per year is a good indication for the instability of slope. Therefore, it is useful to monitor such slow deformations for the early warning and prevention of the landslide disasters [1]. In recent decades, the Interferometric Synthetic Aperture Radar (SAR) (InSAR) technique has been proven to be a powerful tool in this field due to the advantages of being all-day, all-weather, large scale, spatial continuous, high precision and contact-free. Especially with the successively launch of SAR satellites and the great abundance of SAR images, the InSAR technique has entered the era of time series analysis. Many successful applications 
with respect to the monitoring of landslides have been conducted by employing the well-developed multi-temporal InSAR (MT-InSAR) algorithms [2-9].

However, in the landslide-prone area characterized by steep terrain, InSAR measurements from single tracks are vulnerable to the geometric distortions in SAR images (i.e., foreshortening, layover and shadow) [10]. Furthermore, only the line-of-sight (LOS) projection of the three-dimensional (3D) surface deformations can be provided by InSAR measurements, which could induce misinterpretation in the investigating of landslides that always behave as down-slope deformations [11]. These limitations greatly degrade the applicability of InSAR in the landslide monitoring.

Thanks to the increasing number of SAR satellites, multi-sensor datasets with various wavelengths, spatial resolutions and revisiting periods are now available. The L-band SAR data (e.g., Japanese Earth Resources Satellite-1 (JERS-1), Advanced Land Observing Satellite (ALOS) and ALOS-2) can present great performance in the vegetation region due to its good capability of penetration and address relatively large displacement due to its long wavelength [12], but it is quite sensitive to the orbital ramps. The X-band SAR data (e.g., TerraSAR-X and COnstellation of small Satellites for the Mediterranean basin Observation (COSMO)-SkyMed) is usually equipped with high spatial and temporal resolutions. Its applications are, however, limited by the in-demand service and expensive price. The C-band SAR sensors (e.g., ERS-1/2, ENVISAT, RADARSAT-1/2 and Sentinel-1) have the most abundant archived data, whose performance is between the L- and X-band data. In addition, the current SAR satellites can provide the deformation measurements in two LOS directions with ascending and descending tracks. These cross-heading datasets have quite different viewing scenarios in the mountainous areas due to the geometry distortions, but provide a great potential for deriving down-slope deformations for the slow-moving landslides [13]. Therefore, it is very promising to integrate multi-sensor and multi-track SAR data in the investigation of slow-moving landslides [11-19].

In this paper, we integrate $16 \mathrm{~L}$-band ascending SAR images acquired from ALOS satellite and $18 \mathrm{C}$-band descending SAR images acquired from the ENVISAT satellite to investigate the slow-moving landslides in Zhouqu, China. The coverage of the SAR datasets can be found in Figure 1 . Located on the eastern edge of the Qinghai-Tibet Plateau, the Zhouqu area is a typical tectonic erosional mountainous region with an average slope angle of $\sim 30^{\circ}$. Fracture surfaces and quaternary deposits are widely distributed in the study area as a result of the neotectonic movements. The strata in the Zhouqu area are distinguished by alternating soft-hard lithological groups. Influenced by the monsoon climate, the rainfall basically occurs from May to October, accounting for about $90 \%$ of annual precipitation. All of these features are greatly beneficial for the development of landslides [20]. In addition, the ecological environment of Zhouqu is deteriorated by anthropogenic activities such as highway engineering construction. Accordingly, Zhouqu has been suffering from landslide-related geo-hazards for several decades, including the giant debris flow that occurred on 7 August 2010 that caused nearly 1800 deaths [21,22]. Several large landslides such as Suoertou, Nanshanqiaotou and Xieliupo have been found at the both banks of the Pai-lung River, which is the main water source of Zhouqu [23,24]. The S313 Highway, close to the Pai-lung River, is also threatened by the nearby geo-hazards such as the Xieliupo landslide.

The geometric distortions of the ALOS ascending and ENVISAT descending datasets are first assessed according to the SAR imaging geometries and the topography of the Zhouqu area. LOS deformations during 2008-2010 are then estimated from the time series analysis of the ALOS ascending and ENVISAT descending datasets, respectively. Based on the geometric distortion assessments of the cross-heading datasets, down-slope deformations are finally determined by integrating the InSAR LOS measurements from ALOS ascending and ENVISAT descending tracks. 


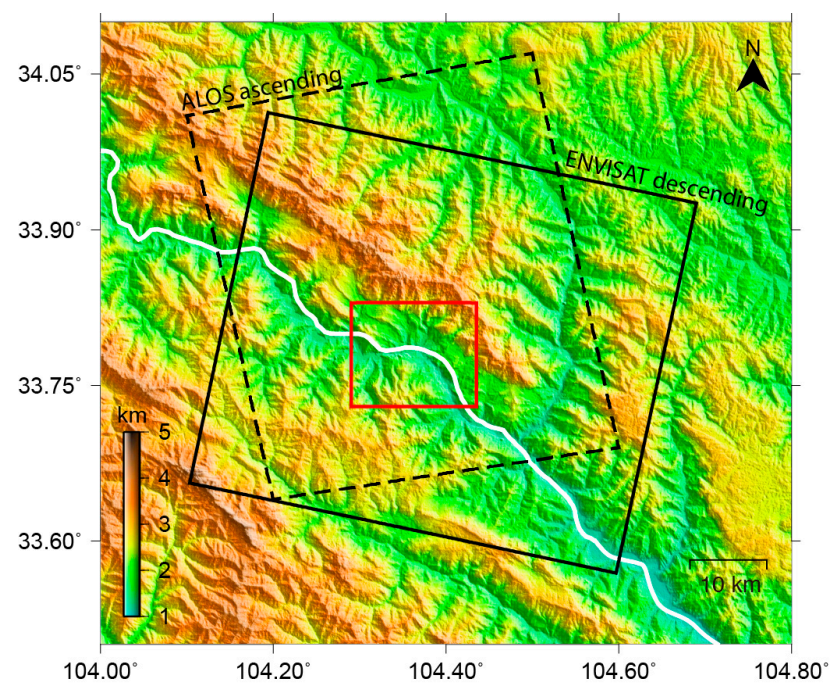

Figure 1. Shaded-relief map of Zhouqu. The red box reveals the scope of the study area. Black real and dashed boxes indicate the coverages of the Advanced Land Observing Satellite (ALOS) ascending and Environmental Satellite (ENVISAT) descending datasets, respectively. The white line represents the Pai-lung River.

\section{Geometric Distortion Determination}

It is acknowledged that the geometric distortions cannot be avoided in the SAR images acquired over mountainous areas due to the side-looking geometries of the current SAR sensors [10]. Figure 2 illuminates how the geometric distortions work in the SAR images. For the slopes dipping towards the SAR sensor, when the local terrain slope angle $\chi$ is smaller than the local incidence angle $\theta$, such slopes have a shorter length in the SAR image than on the flat terrain, which means the range resolution on such slopes becomes worse. This is the so-called foreshortening effect, which achieves worst performance when $\chi$ equals to $\theta$. Furthermore, when $\chi$ is larger than $\theta$, the bottom and the top of such slopes are reversedly imaged, known as the layover effect. Generally, the layover-occurring slopes are much brighter than other places on the SAR image. For the slopes dipping away from the SAR sensor, when $\chi$ is smaller than $90^{\circ}-\theta$, the range resolution on such slopes becomes better in the SAR images than on flat terrain. Obviously, the resolution-enhancing effect is popular with InSAR measurements. However, when $\chi$ exceeds $90^{\circ}-\theta$, such steep slopes are completely prevented from receiving the SAR signal by the mountain itself. This is the shadow effect that makes the slopes dark in the SAR image. For more details on geometric distortion analysis, see [10].

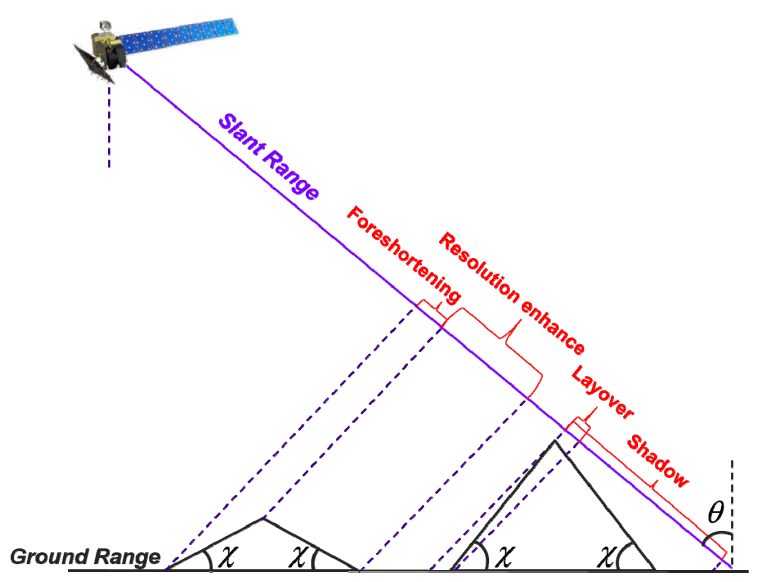

Figure 2. Geometric distortion effects in the Synthetic Aperture Radar (SAR) image. 
Therefore, the InSAR measurements will be distorted in the areas affected by foreshortening and be completely impaired in the areas affected by layover and shadow. In general, the SAR images with mean incidence angle close to $45^{\circ}$ are suitable for the area characterized by steep relief, since the shadow and layover cumulated effects would be minimized in such measurements [10]. For the InSAR measurements acquired from ascending tracks (flying from approximately south towards north) and descending tracks (flying from approximately north towards south), the geometric distortions will occur in quite different areas, resulting in inconsistent and even contradictory validities. Therefore, before employing and integrating the SAR datasets from multi-sensor and multi-track data, we should discriminate the respective areas affected by different kinds of geometric distortions.

In this study, the ALOS ascending images and ENVISAT descending images collected over the Zhouqu area are investigated for their geometric distortions. The local incidence angle $\theta$ and the azimuth angle $\alpha$ for the used ALOS ascending data are shown in Figure 3a,b, respectively. $\alpha$ is also the flight angle of SAR satellite, which is clockwise from the north. It is observed that $\theta$ of the used ALOS ascending data ranges from $36.4^{\circ}$ (near range) to $38.7^{\circ}$ (far range), while $\alpha$ of the used ALOS ascending data is approximately $-10.3^{\circ}$ (at mid-range). Figure $3 \mathrm{c}, \mathrm{d}$ show $\theta$ and $\alpha$ for the used ENVISAT descending data, respectively. $\theta$ of the used ENVISAT descending data, varying from $20.2^{\circ}$ (near range) to $23.0^{\circ}$ (far range), is smaller than that of ALOS ascending data. $\alpha$ of the ENVISAT descending data is around $192.1^{\circ}$ (at mid-range). All of the angles behave as gradually varying ramps.

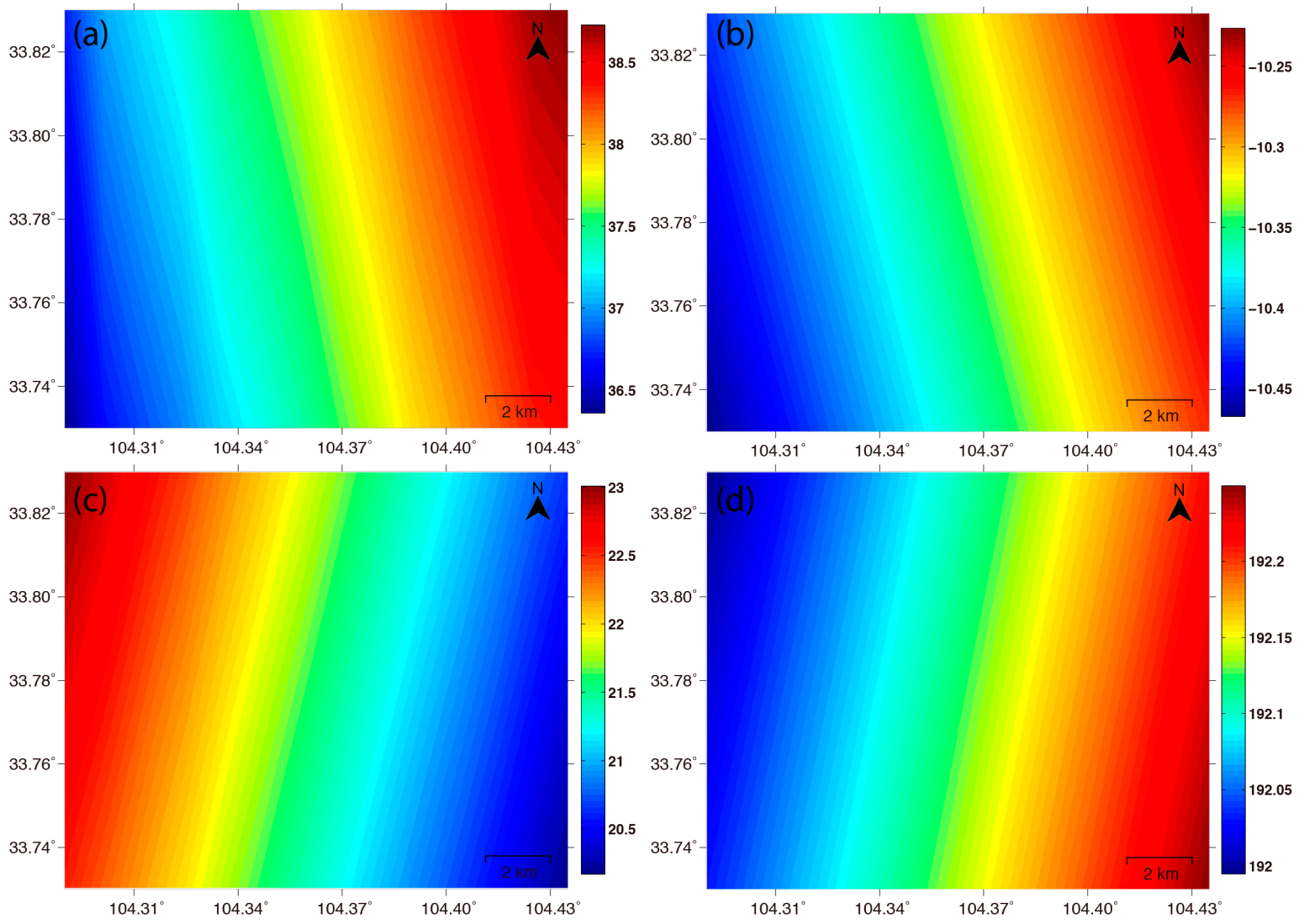

Figure 3. $(\mathbf{a}, \mathbf{b})$ local incidence angle $\theta$ and the azimuth angle $\alpha$ for the used ALOS ascending data; (c,d) local incidence angle $\theta$ and the azimuth angle $\alpha$ for the used ENVISAT descending data.

The local terrain slope angle $\chi$ and the local terrain aspect angle $\gamma$ for the study area are estimated from the 1 arcsec Advanced Spaceborne Thermal Emission and Reflection Radiometer Global Digital Elevation Model (ASTER GDEM) data. As shown in Figure 4a, the Zhouqu area is characterized by mountainous terrain, with an average $\chi$ of $31.5^{\circ}$. Although $\chi$ reaches $74.6^{\circ}$ for the largest slope angle, 
the terrain is relatively flat near the Pai-lung River. With respect to the local terrain aspect angle $\gamma$, which is also clockwise from the north, it is found in Figure $4 \mathrm{~b}$ that the slopes in the Zhouqu area have quite complicated orientations, ranging from $-88.2^{\circ}$ to $267.7^{\circ}$.

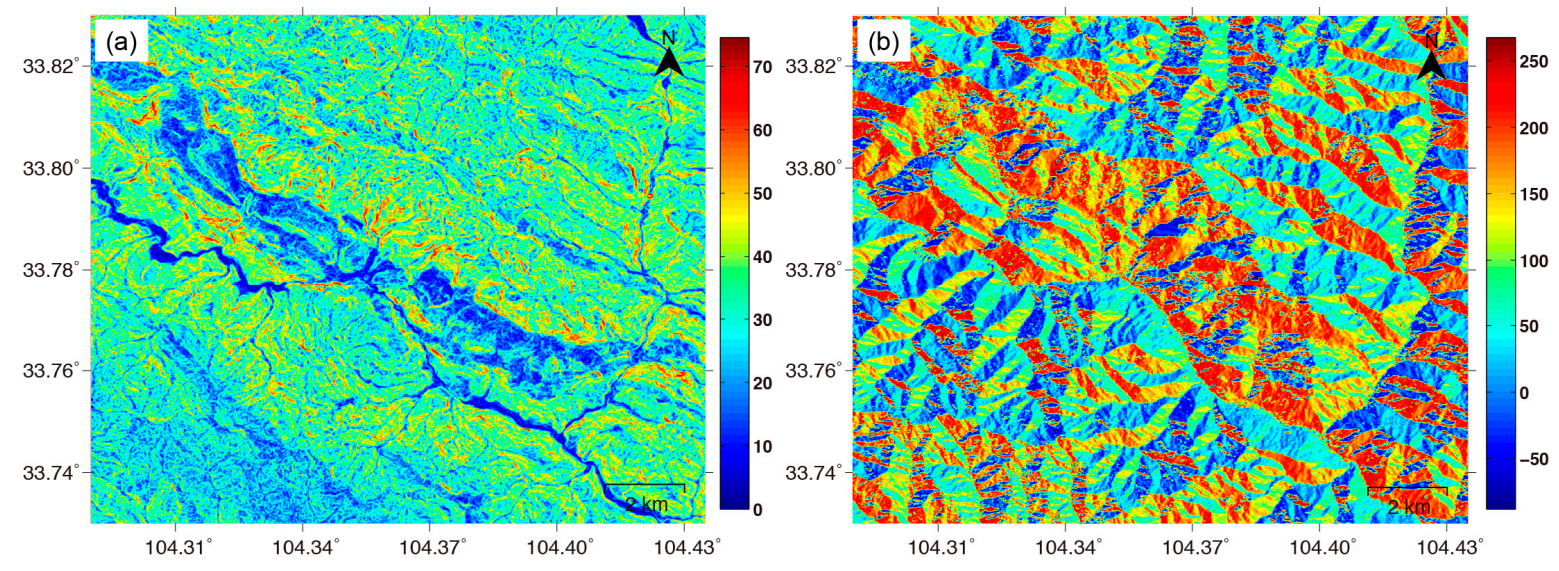

Figure 4. Local terrain slope angle $\chi(\mathbf{a})$ and local terrain aspect angle $\gamma(\mathbf{b})$ for the study area.

By providing the SAR imaging geometries (i.e., $\theta$ and $\alpha$ ) and the local terrain information (i.e., $\chi$ and $\gamma$ ), the areas affected by the geometric distortions can thus be mapped for the collected ALOS ascending and ENVISAT descending images, respectively. Figure 5a shows the geometric distortions of the ALOS ascending data in the Zhouqu area. Although some areas are affected by layover, most of the areas are dominated by the resolution-enhancing effect, demonstrating that the ALOS ascending data is very suitable for the monitoring of the Zhouqu area. The geometric distortions of the ENVISAT descending data are shown in Figure 5b. Clearly, nearly half of the areas are affected by layover, indicating that the application of the ENVISAT descending data is quite limited in the Zhouqu area. However, the usable InSAR measurements could be obtained from the ENVISAT descending data in the resolution-enhancing and foreshortening regions. In addition, the shadow regions are quite seldom in both images, especially the ENVISAT descending one. This benefits from the relatively small incidence angles of the SAR satellite. In total, it can be inferred that, in the Zhouqu area, the ALOS ascending data is more suitable to investigate the slow-moving landslides than the ENVISAT descending data.

It can also be observed in Figure 5 that the geometric distortions of the ALOS ascending and ENVISAT descending data are quite complementary, i.e., the regions affected by severe geometric distortions (i.e., layover and shadow effects) in the ALOS ascending image correspond to the regions being appropriate for InSAR measurements (i.e., resolution-enhancing and foreshortening effects) in the ENVISAT descending image, and vice versa. Obviously, employment of multi-sensor and multi-track SAR data can greatly improve the coverage of InSAR measurements, but it is also a great challenge to integrate multi-sensor and multi-track InSAR measurements due to the limited common usable areas. Figure 6 exhibits the integrating result of the geometric distortions of the ALOS ascending and ENVISAT descending data. As expected, the areas, where both of the cross-heading data can acquire usable measurements, are generally characterized by flat terrain. Meanwhile, there are also very limited areas that are appropriate for neither one. 

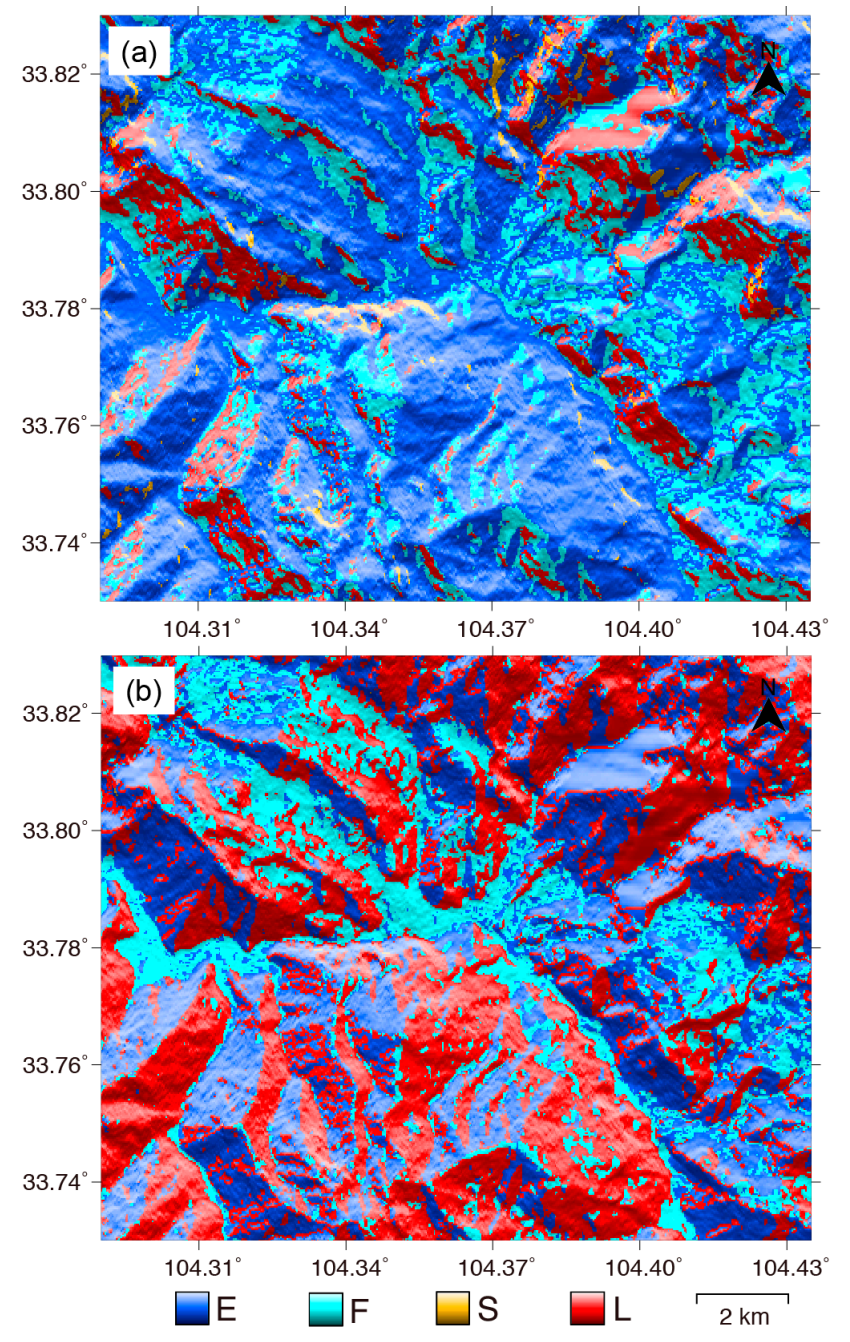

Figure 5. Geometric distortions in the ALOS ascending (a) and ENVISAT descending (b) images acquired over Zhouqu. E: Resolution-Enhancing; F: Foreshortening; S: Shadow; L: Layover.

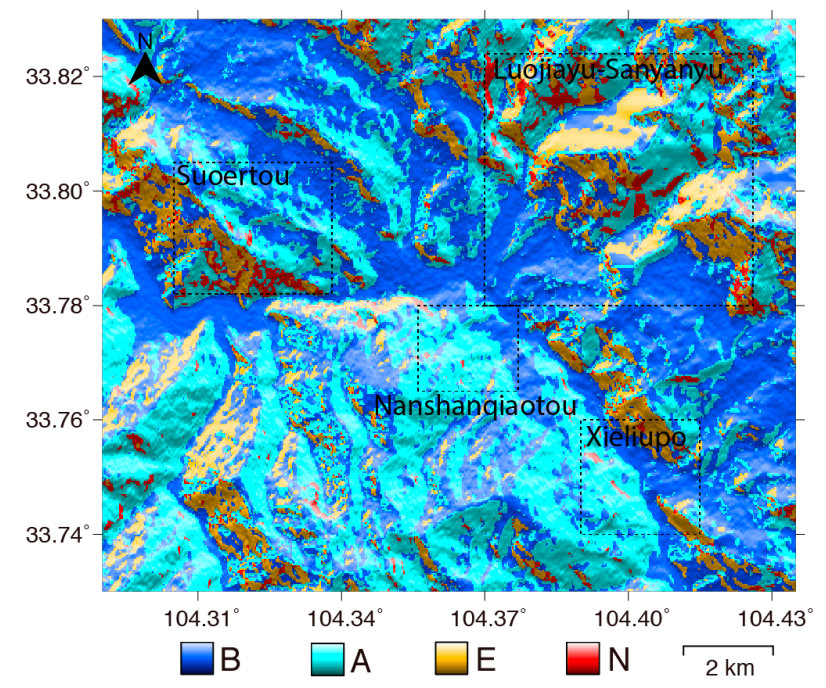

Figure 6. Integrating result of the geometric distortions of the ALOS ascending and ENVISAT descending data. B: appropriate for both data; A: appropriate for ALOS data; E: appropriate for ENVISAT data; N: appropriate for neither data. 


\section{InSAR Time Series Analysis}

We employ the Temporarily Coherent Point (TCP)-InSAR algorithm $[25,26]$ in this study to conduct InSAR time series analysis. By exploiting the phase differences between the adjacent temporarily coherent points (TCPs) in the multi-master interferograms, the TCP-InSAR algorithm combines the advantages of the classical permanent scattered (PS) and small baseline subsets (SBAS) algorithms, and has been successfully applied in the monitoring of tectonic movements [25], ground subsidence [27], and landslides [28].

In the processing of TCP-InSAR, 19 and 13 small-baseline interferograms are generated from the 16 ALOS ascending and 18 ENVISAT descending images, respectively. The time spans of the ALOS and ENVISAT datasets are from 28 January 2008 to 23 June 2010 and from 24 December 2007 to 17 May 2010, respectively. Since the C-band ENVISAT data is much more sensitive to the spatial-temporal decorrelations than the L-band ALOS data, 70 days for time interval and $70 \mathrm{~m}$ for perpendicular baseline are chosen as the spatial-temporal baseline thresholds for the ENVISAT descending interferograms, while 600 days and $750 \mathrm{~m}$ are used for the ALOS ascending interferograms. The spatial-temporal baselines of the generated interferograms can be found in Figure 7. The phase noises in the interferograms are reduced by the multi-look operation (six looks in range and 14 looks in azimuth for ALOS, and two looks in range and 10 looks in azimuth for ENVISAT), yielding a spatial resolution of about $40 \mathrm{~m}$. The 1 arcsec ASTER GDEM data of Zhouqu is employed to remove the topographic effect. Since the small-baseline interferograms, especially those generated from the ENVISAT data, are divided into several subsets, we focus on retrieving the deformation rates from the time series analysis.
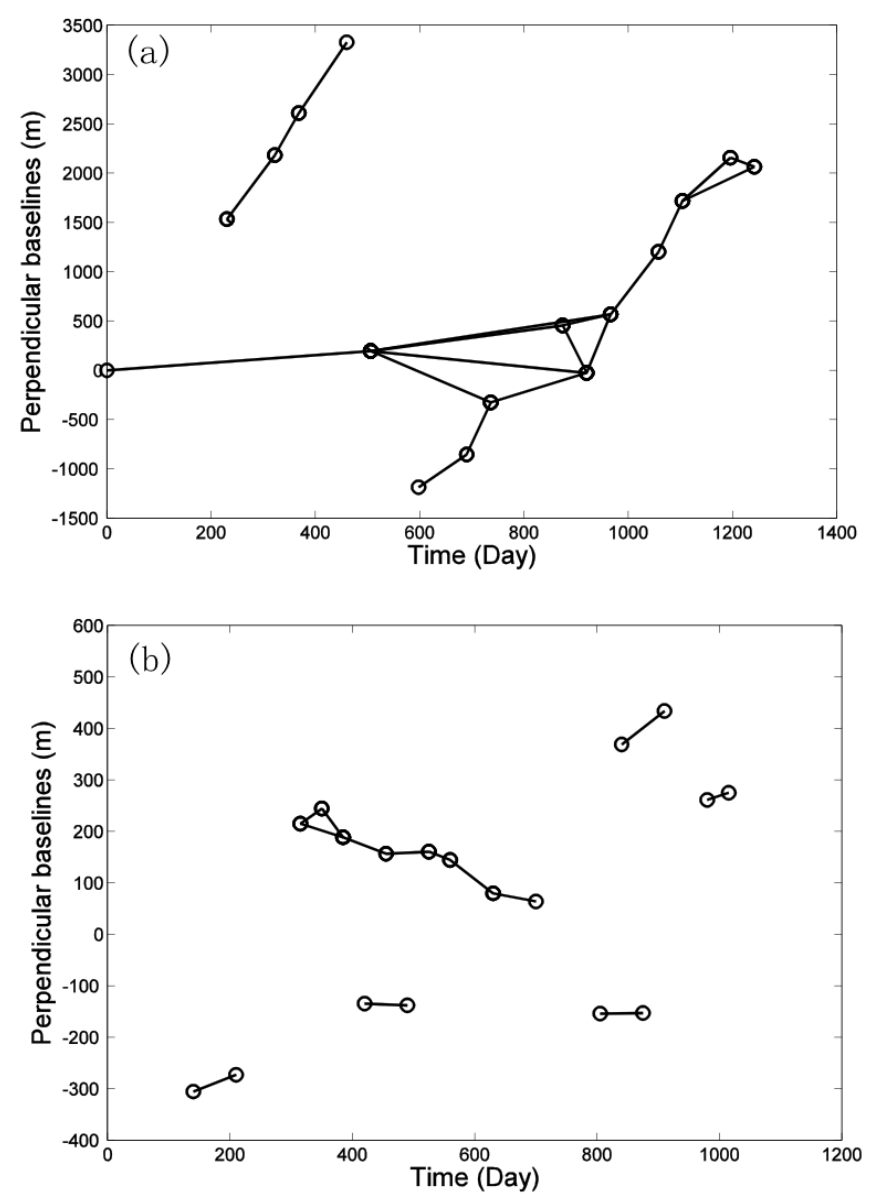

Figure 7. Spatial-temporal baselines of the generated ALOS ascending (a) and ENVISAT descending (b) interferograms. Circles and lines represent SAR images and interferometric pairs, respectively. 
Figure 8a,b show the TCP-InSAR derived LOS deformation rate fields from ALOS ascending and ENVISAT descending datasets, respectively. Obviously, the coverage of the ALOS deformation field is much larger than that of the ENVISAT deformation field. This is expected since the areas affected by severe geometric distortions in the ENVISAT data are much more than those in the ALOS data. In addition, C-band ENVISAT data is more vulnerable to the vegetation due to its relatively weaker penetration.
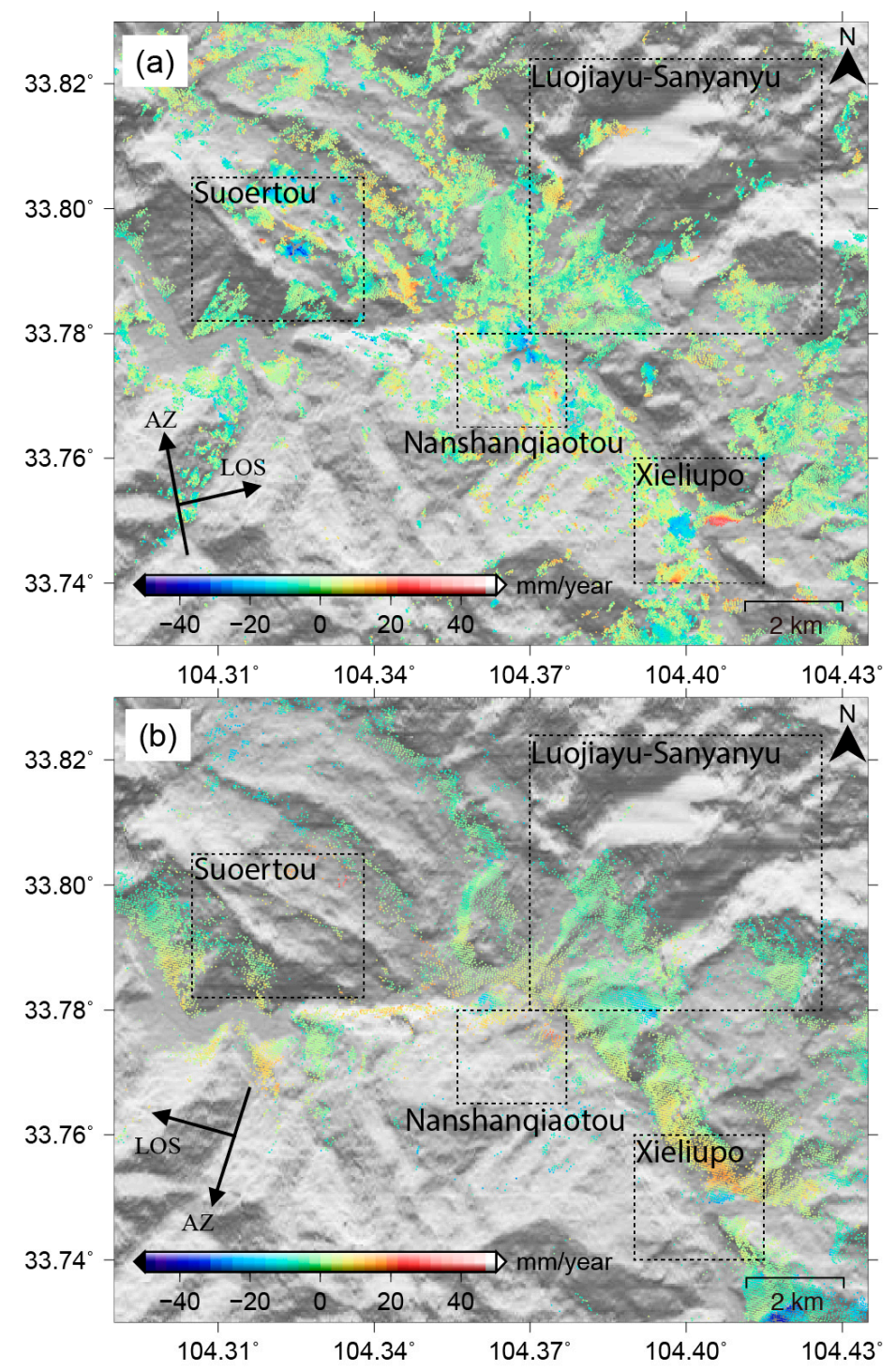

Figure 8. LOS deformation rate fields over the study area estimated from ALOS ascending (a) and ENVISAT descending (b) datasets, respectively, which are superimposed on Advanced Spaceborne Thermal Emission and Reflection Radiometer Global Digital Elevation Model (ASTER GDEM)-derived topography. AZ and LOS indicate the azimuth and the LOS directions, respectively. Dashed boxes indicate the regions affected by the landslides.

As outlined by dashed boxed in Figure 8, there are mainly four regions affected by the slow-moving landslides, including Luojiayu-Sanyanyu, Suoertou, Nanshanqiaotou and Xieliupo [9]. In the Luojiayu-Sanyanyu region, where the giant mudslide occurred on 7 August 2010, it is found that neither of ALOS and ENVISAT data acquires sufficient TCPs. In the Suoertou and Nanshanqiaotou regions, although slow-moving landslides have been detected in the ALOS data, they are unavailable in the ENVISAT data. The most ideal results have been obtained in the Xieliupo region, where both 
ALOS and ENVISAT data have detected obvious deformation signals on the east coast of the Pai-lung River. The TCPs in the Xieliupo region retrieved from the ALOS and ENVISAT data are superimposed on their respective geometric distortions, as shown in Figure 9a,b, respectively. As expected, most of the TCPs are distributed in the resolution-enhancing regions. A small number of TCPs are located in the foreshortening regions, which are characterized by gentle terrain. However, several individual TCPs are found in the layover and shadow regions. This could be ascribed to the errors of the geo-location of radar scatterers [29]. Figure 9c,d exhibit the LOS deformation velocity fields of the Xieliupo region estimated from the ALOS ascending and ENVISAT descending datasets, respectively, which are superimposed on the optical image. Obviously, both coasts of the Pai-lung River have been found to experience slow-moving landslides in the ALOS ascending results, while in the ENVISAT descending results, we only detect slow-moving landslides on the east coast of the Pai-lung River. It can also be found that the LOS deformation rates on the east coast of the Pai-lung River are opposite between the ALOS ascending and ENVISAT descending results. This is expected since the down-slope landslides on the east coast of the Pai-lung River are dominated by the horizontal deformations, which move toward the SAR satellites in the ascending track but away from those in the descending track.
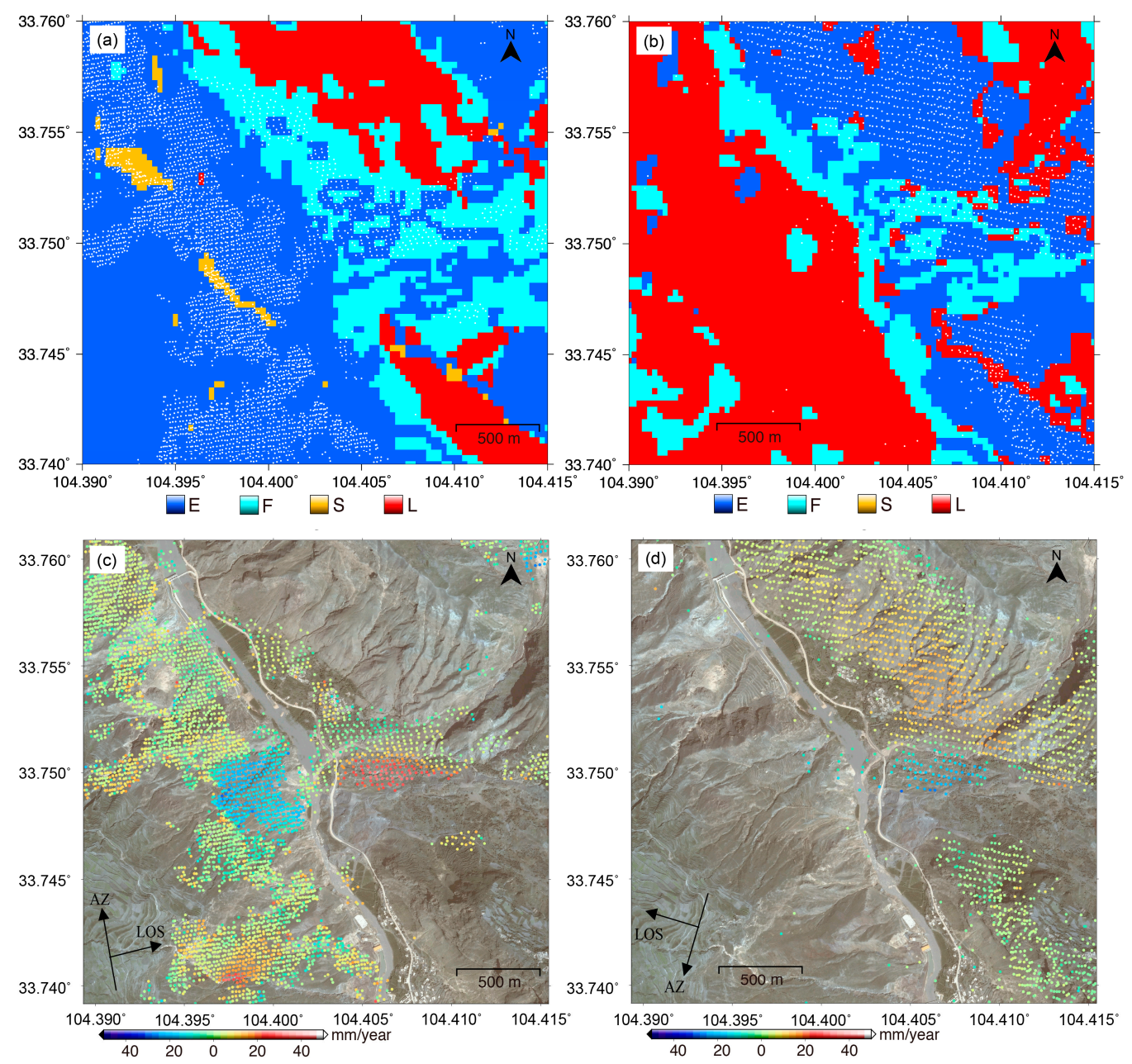

Figure 9. (a,b) locations of temporarily coherent points (TCPs) in Xieliupo region derived from ALOS ascending and ENVISAT descending results, respectively, which are superimposed on the corresponding geometric distortions. E: Resolution-Enhancing; F: Foreshortening; S: Shadow; L: Layover; (c,d) LOS deformation rates at the Xieliupo region estimated from ALOS ascending and ENVISAT descending datasets, respectively, which are superimposed on the optical image. AZ and LOS indicate the azimuth and the LOS directions, respectively. 


\section{Integration of Multi-Sensor InSAR}

The availability of ALOS and ENVISAT measurements in the Xieliupo region provides us an opportunity to estimate real 3D deformations for the slow-moving landslide. In theory, 3D surface deformation can be resolved by integrating InSAR measurements acquired in at least three distinct LOS directions [30,31]. However, since all the current SAR satellites fly in the polar orbits, except in the polar region, the InSAR Line-Of-Sight (LOS) measurements with two distinct imaging geometries can only be provided by the ascending and descending tracks [31]:

$$
\left[\begin{array}{c}
v_{a s} \\
v_{d e s}
\end{array}\right]=\left[\begin{array}{ccc}
a_{a s} & b_{a s} & c_{a s} \\
a_{d e s} & b_{d e s} & c_{d e s}
\end{array}\right] \cdot\left[\begin{array}{c}
v_{u} \\
v_{e} \\
v_{n}
\end{array}\right],
$$

where $v_{u}, v_{e}$ and $v_{n}$ are the deformation rates in the up, east and north directions, respectively. $v_{a s}$ and $v_{d e s}$ are the ascending and descending InSAR LOS measurements, respectively. $\left[a_{a s}, b_{a s}, c_{a s}\right]$ and $\left[a_{\text {des }}, b_{\text {des }}, c_{d e s}\right]$ represent the projection coefficients for the ascending and descending tracks, respectively, which can be estimated based on the imaging geometries.

Azimuth measurements provided by the Offset-Tracking and multi-aperture InSAR techniques can be employed to aid InSAR LOS measurements in the resolving 3D deformations associated with events such as earthquake [32], volcano eruption [33] and glacier movement [34]. This method is, however, not suitable in the investigation of slow-moving landslides due to the relatively low accuracies of the azimuth measurements.

With respect to the fact that slow-moving landslides basically deform along the slope's surface, $3 \mathrm{D}$ deformations are actually equivalent to the down-slope deformations. A surface-parallel flow assumption can thus be made [35]:

$$
v_{u}=v_{e} \cdot s_{e}+v_{n} \cdot s_{n},
$$

where $s_{e}$ and $s_{n}$ represent the surface slopes along the east and north directions, respectively, which can be estimated based on the terrain information provided by the external DEM (e.g., ASTER GDEM) [36]. Noteworthy is the fact that the surface-parallel flow assumption has limitations when the slow-moving landslides have a complex behavior such as rotational motion. Therefore, the assumption aims only to produce a qualified estimate of the 3D deformations. Equations (1) and (2) can then be combined into:

$$
\left[\begin{array}{c}
v_{a s} \\
v_{d e s} \\
0
\end{array}\right]=\left[\begin{array}{ccc}
a_{a s} & b_{a s} & c_{a s} \\
a_{d e s} & b_{d e s} & c_{d e s} \\
-1 & s_{e} & s_{n}
\end{array}\right] \cdot\left[\begin{array}{c}
v_{u} \\
v_{e} \\
v_{n}
\end{array}\right],
$$

Three-dimensional deformation rates of a slow-moving landslide can thus be resolved by applying a least squares adjustment to Equation (3). It should be noted that the validity of Equation (3) is based on the hypothesis of constant deformation rates, which, however, cannot be completely satisfied since on most landslides the deformation has seasonal and multiannual variations. Accordingly, the estimations of the 3D deformations could be hampered by such hypothesis. In addition, the accuracies of the estimated east and north deformation rates highly depend on the surface slopes along the corresponding directions. For instance, for the slope facing towards the east, accurate north deformation estimation cannot be guaranteed since the north surface slope $s_{n}$ is close to zero. In such cases, inequality constraints can be added to Equation (3) by providing the reasonable intervals to the 3D estimations [37].

Three-dimensional deformation rates are estimated for the Xieliupo region from the ALOS ascending and ENVISAT descending LOS measurements based on Equation (3). Since the locations of the TCPs are not completely consistent for the ascending and descending results, they have been resampled into a uniform grid before the integration. The 3D deformation rates of the Xieliupo landslide are shown in Figure 10, where the color and the arrow represent the vertical and horizontal 
deformation velocities, respectively. It is clearly found that the Xieliupo landslide is dominated by downward as well as westward movements. The maximum horizontal and vertical deformation velocities reach -55 and $-16 \mathrm{~mm} /$ year, respectively. The scope of the Xieliupo landslide is outlined by the dashed line [38]. As expected, the regions out of the Xieliupo landslide affected zone are relative stable, with most of the down-slope velocities being smaller than $5 \mathrm{~mm} /$ year. A significant down-slope deformation occurs in the transport zone, uniformly exceeds $20 \mathrm{~mm} /$ year and locally exceeds $40 \mathrm{~mm}$ /year. Relative low rates of down-slope deformation ( $10 \mathrm{~mm} /$ year) are detected in the toe of the Xieliupo landslide, near the Pai-lung River. It is found that the down-slope velocities increase at a distance of $800 \mathrm{~m}$ to the Pai-lung River, and then turns to deceleration at a distance of $400 \mathrm{~m}$ to the Pai-lung River. However, we cannot provide the quantitative results for the accuracies of the InSAR-measured deformations due to the unavailability of the field observations in the area. We also observe that the deformation result is absent in the southern and eastern portions of the Xieliupo slope. This, however, does not indicate negligible deformation in these regions, but instead reflects the lack of TCPs found in either the ALOS ascending or ENVISAT descending datasets. Actually, in these regions, obvious fringe patterns can be observed on the shortest time-spans (i.e., 46 days) ALOS interferograms, but are obscured by great phase noises on the other ALOS interferograms and all the ENVISAT interferograms. With respect to the moderate vegetation and the gentle incline of the Xieliupo slope, these fringes are very likely caused by the relatively large deformations, indicating that fast landslides at a level of $\mathrm{m} /$ year occur in the southern and eastern portions of the Xieliupo slope. These fast movements have also been reported in [38].

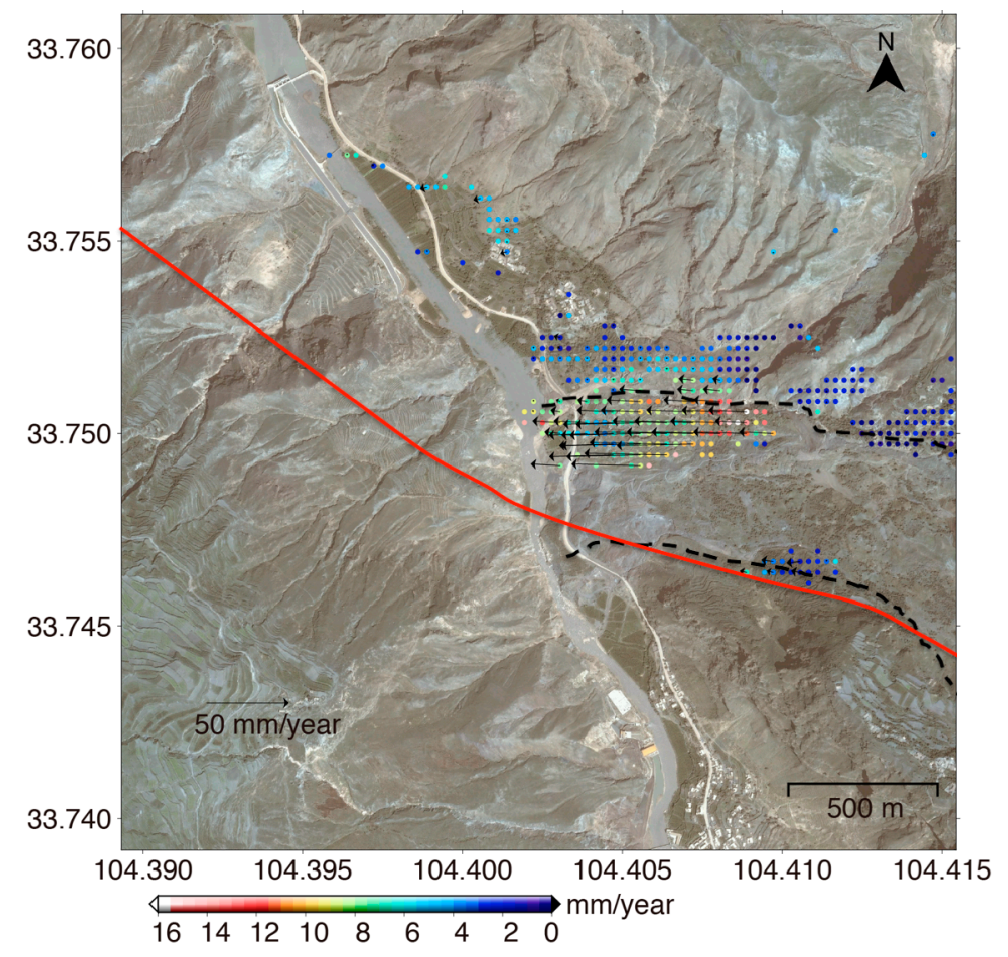

Figure 10. 3D deformation rates of the Xieliupo landslide, where the color and the arrow represent the vertical and horizontal deformation velocities, respectively. Black dashed line outlines the scope of the Xieliupo landslide [38]. Red line marks the location of Pingding-Huama fault [38].

\section{Discussion}

The case study that we have conducted in the Zhouqu area has shown that the multi-sensor and multi-track SAR datasets are quite useful for slow-moving landslide assessment, but still remain challenging since the LOS deformations retrieved from different tracks and sensors are heterogeneous. 
First, our experiment has shown the capability of the SAR data captured by the ALOS ascending track and ENVISAT descending track for landslide detection. Although the performance of InSAR measurements depends on many factors such as the growth of vegetation and the length of observation period, geometric distortion effects are of great importance for the investigating of landslides that are generally in the mountainous environment. In the Zhouqu area, the regions affected by different geometric distortions (including resolution-enhancing, foreshortening, layover and shadow) are determined by the ALOS ascending and ENVISAT descending datasets according to the imaging geometries and the local terrain (Figure 5). The geometric distortion results provide us a whole picture of understanding how the InSAR technique performs in the study area. It is acknowledged that the InSAR measurements become invalid in the layover and shadow regions. However, the degradation of the performance of the InSAR measurements in the foreshortening regions depends on effective resolution of SAR data. On the regional scale, this is also valuable information for the selection of the most appropriate SAR data for a particular slope. In addition, we outline the integrating results of geometric distortions of the cross-heading datasets (Figure 6). This opens up the possibility of estimating 3D deformations of the slow-moving landslides. The spatial resolution of the used DEM data is critical for the accuracy of the geometric distortions [10]. The spatial resolution of the used ASTER GDEM is $30 \mathrm{~m}$, which is comparable to that of the TCP-InSAR measurements. It is found that most of the TCPs locate in the regions affected by resolution-enhancing. It should, however, be noted that the spatial-temporal decorrelation cannot be reflected by the geometric distortions. Therefore, radar wavelength and surface coverage should be involved to determine the density of the TCPs in the future [39].

Second, we exploit the TCP-InSAR technique to analyse multi-sensor SAR time series datasets to present the LOS deformation rate maps for the active landslides in the Zhouqu area. Heterogeneous displacement rates are detected in the ALOS ascending and ENVISAT descending measurements. More specific comparative assessments of the ALOS ascending and ENVISAT descending results are made by focusing on an unstable slope at Xieliupo. The detected displacement rates on the east coast of the Pai-lung River are found to be completely different (Figure 9). This is, however, reasonable by considering the effects of the slope facing and inclination as well as the imaging geometries of the different sensors on the interpretation. In order to reduce the heterogeneity, 3D deformation rates of the Xieliupo landslide are determined by integrating the multi-sensor TCP-InSAR measurements on the basis of the surface-parallel flow assumption (Figure 10). Non-uniform deformations are observed at the frontal region of the Xieliupo landslide, close to the Pai-lung River. As a gravity-driven landslide, it is natural that the velocities of the Xieliupo landslide increase at the upper half of the transport zone, as a result of the increased loose materials brought by the landslide flow. However, the reduction of the rates at the bottom half of the transport zone cannot be completely explained by the gravity since the slopes do not vary much at the frontal region. A possibility is that the loose materials have been cleaned up by the maintenance projects of the S313 Highway, which crosses over the frontal edge of the landslide. The erosion effect of the Pai-lung River on the frontal edge can almost be neglected since both the water level and speed are degraded by the diversion of the Hujiaya Hydropower Station that was built in 2004 [40]. Therefore, it can be inferred that at the northern part the Xieliupo landslide does not directly bring material into the Pai-lung River. The absence of the InSAR measurement in the southern part of the Xieliupo landslide cannot be ascribed to the geometric distortion (Figure 10). The main factor is the drastic surface changes caused by, for example, fast ground movements. It has been demonstrated that the left-lateral strike-slips of the Pingding-Huama fault, which almost parallels with the southern margin of the Xieliupo landslide, have greatly accelerated the landslide movements at its nearby regions $[38,40,41]$. Deformation time series are, however, not obtained since the small-baseline interferograms generated from the ENVISAT data belong to separate subsets with great temporal gaps. This prohibits the investigation of the long-term kinematical behavior of the landslides in the study area. 
The performances of X-band SAR data such as COSMO-SkyMed and TerraSAR-X in the landslide detection are not investigated at the current stage. Higher density of TCPs can be expected from these X-band SAR data, as a result of the higher resolution and shorter revisit period compared to those of ENVISAT and ALOS SAR data. We consider the experiment conducted in the Zhouqu area as a prototype example of the employment of multi-sensor data in the investigations of the slow-moving landslides, especially for the successors of L- and C-band satellites, i.e., ALOS-2 and Sentinel-1. We can expect the improvement of the future products in the monitoring of landslides due to the better characteristics of the new sensors. For instance, thanks to the higher resolution and repetitiveness of ALOS-2 and Sentinel- 1 data, it is possible to address the landslides of smaller sizes and faster movements than those measured in this study. Furthermore, we can demand higher incidence angles (i.e., $>40^{\circ}$ ) for the SAR images acquired over areas with steep relief (e.g., Zhouqu) in order to better suppress the geometric distortions. The combined use of the InSAR measurements from different sensors and different tracks maximizes the potentials of these different datasets, e.g., the comprehensive coverage for the monitoring of active landslide areas, and 3D deformation maps for an appropriate slope.

\section{Conclusions}

An integration of ALOS and ENVISAT data acquired over Zhouqu, China has been carried out to exploit the possibility of investigating slow-moving landslides. A multi-sensor system has not been employed to examine the Zhouqu landslides in the previous studies. As a result, the down-slope movements of the Zhouqu landslides were poorly detected. We firstly investigate the geometric distortions for the ALOS ascending and ENVISAT descending datasets, and then perform InSAR time series analysis to retrieve deformations during 2008-2010 for the unstable slopes in the Zhouqu area. The main conclusions of this study are deduced as follows:

(1) By employing the imaging geometric parameters of the SAR sensor and the external DEM data of the study area, the geometric distortion effects are determined for SAR images acquired from ALOS ascending and ENVISAT descending tracks. We find that cross-heading SAR data are inferior to the single track SAR data in the avoiding of the geometric distortion effects, since the layover and shadow regions in the ascending images basically correspond to the resolution-enhancing and foreshortening regions in the descending images, and vice versa. The comparison and combination of the cross-heading data derived geometric distortions allows the integration of the InSAR measurements in the regions being appropriate for multi-sensor and multi-track data, such as the Xieliupo region.

(2) The LOS deformation rate fields of the Zhouqu area are estimated with the TCP-InSAR algorithm from 16 ALOS ascending and 18 ENVISAT descending datasets, respectively. The locations of the retrieved TCPs agree well with the prior determined geometric distortions affected regions. As expected, the ALOS ascending deformation result is better than the ENVISAT descending deformation result in the detection of the slow-moving landslides in Zhouqu. In the Xieliupo region, 3D deformation rates are reconstructed from the integration of the cross-heading TCP-InSAR results based on the surface-parallel flow assumption. Compared to the LOS deformation results, the 3D deformation results more clearly exhibit the amplitude as well as the direction of the earth flow on the east bank of the Pai-lung River. This provides us with a comprehensive insight into understanding the threats of the potential hazards such as dammed lakes. 
Acknowledgments: The used ALOS and ENVISAT data were from the Japan Aerospace Exploration Agency (JAXA) and the European Space Agency (ESA), respectively. The research was supported by the National Key Basic Research and Development Program of China (No. 2013CB733303), the Research Grants Council (RGC) of the Hong Kong Special Administrative Region (Project Nos. PolyU 152214/14E, PolyU 152043/14E), and the National Natural Science Foundation of China (Nos. 41604010, 41404011, 41304011, 41374013).

Author Contributions: Q.S. and J.H. conceived and designed the experiments; Q.S. performed the experiments; J.H. and L.Z. analyzed the data; X.D. contributed to the discussions of the results; and Q.S. wrote the paper. All authors reviewed and approved the manuscript.

Conflicts of Interest: The authors declare no conflict of interest.

\section{References}

1. Angeli, M.G.; Pasuto, A.; Silvano, S. A critical review of landslide monitoring experiences. Eng. Geol. 2000, 55, 133-147. [CrossRef]

2. Hilley, G.E.; Burgmann, R.; Ferretti, A.; Novali, F.; Rocca, F. Dynamics of slow-moving landslides from permanent scatterer analysis. Science 2004, 304, 1952-1955. [CrossRef] [PubMed]

3. Cascini, L.; Fornaro, G.; Peduto, D. Advanced low- and full-resolution DInSAR map generation for slow-moving landslide analysis at different scales. Eng. Geol. 2010, 112, 29-42. [CrossRef]

4. Zhao, C.; Lu, Z.; Zhang, Q.; de La Fuente, J. Large-area landslide detection and monitoring with ALOS/PALSAR imagery data over Northern California and Southern Oregon, USA. Remote Sens. Environ. 2012, 124, 348-359. [CrossRef]

5. Tofani, V.; Raspini, F.; Catani, F.; Casagli, N. Persistent Scatterer Interferometry (PSI) technique for landslide characterization and monitoring. Remote Sens. 2013, 5, 1045-1065. [CrossRef]

6. Tantianuparp, P.; Shi, X.; Zhang, L.; Balz, T.; Liao, M. Characterization of landslide deformations in three gorges area using multiple InSAR data stacks. Remote Sens. 2013, 5, 2704-2719. [CrossRef]

7. Liu, P.; Li, Z.; Hoey, T.; Kincal, C.; Zhang, J.; Zeng, Q.; Muller, J.P. Using advanced InSAR time series techniques to monitor landslide movements in Badong of the Three Gorges region, China. Int. J. Appl. Earth Obs. 2013, 21, 253-264. [CrossRef]

8. Tang, P.P.; Chen, F.L.; Guo, H.D.; Tian, B.S.; Wang, X.Y.; Ishwaran, N. Large-Area Landslides Monitoring Using Advanced Multi-Temporal InSAR Technique over the Giant Panda Habitat, Sichuan, China. Remote Sens. 2015, 7, 8925-8949. [CrossRef]

9. Sun, Q.; Zhang, L.; Ding, X.L.; Hu, J.; Li, Z.W.; Zhu, J.J. Slope deformation prior to Zhouqu, China landslide from InSAR time series analysis. Remote Sens. Environ. 2015, 156, 45-57. [CrossRef]

10. Colesanti, C.; Wasowski, J. Investigating landslides with space-borne Synthetic Aperture Radar (SAR) interferometry. Eng. Geol. 2006, 88, 173-199. [CrossRef]

11. Herrera, G.; Gutierrez, F.; Garcia-Davalillo, J.C.; Guerrero, J.; Notti, D.; Galve, J.P.; Fernandez-Merodo, J.A.; Cooksley, G. Multi-sensor advanced DInSAR monitoring of very slow landslides: The Tena Valley case study (Central Spanish Pyrenees). Remote Sens. Environ. 2013, 128, 31-43. [CrossRef]

12. Delacourt, C.; Raucoules, D.; Le Mouelic, S.; Carnec, C.; Feurer, D.; Allemand, P.; Cruchet, M. Observation of a Large Landslide on La Reunion Island Using Differential Sar Interferometry (JERS and Radarsat) and Correlation of Optical (Spot5 and Aerial) Images. Sensors 2009, 9, 616-630. [CrossRef] [PubMed]

13. Raucoules, D.; de Michele, M.; Malet, J.P.; Ulrich, P. Time variable 3D ground displacements from high-resolution synthetic aperture radar (SAR). Application to La Valette landslide (South French Alps). Remote Sens. Environ. 2013, 139, 198-204. [CrossRef]

14. Calo, F.; Ardizzone, F.; Castaldo, R.; Lollino, P.; Tizzani, P.; Guzzetti, F.; Lanari, R.; Angeli, M.G.; Pontoni, F.; Manunta, M. Enhanced landslide investigations through advanced DInSAR techniques: The Ivancich case study, Assisi, Italy. Remote Sens. Environ. 2014, 142, 69-82. [CrossRef]

15. Bovenga, F.; Wasowski, J.; Nitti, D.O.; Nutricato, R.; Chiaradia, M.T. Using COSMO/SkyMed X-band and ENVISAT C-band SAR interferometry for landslides analysis. Remote Sens. Environ. 2012, 119, 272-285. [CrossRef]

16. Chen, F.; Lin, H.; Hu, X. Slope superficial displacement monitoring by small baseline SAR interferometry using data from L-band ALOS PALSAR and X-band TerraSAR: A case study of Hong Kong, China. Remote Sens. 2014, 6, 1564-1586. [CrossRef] 
17. Shi, X.G.; Zhang, L.; Liao, M.S.; Balz, T. Deformation monitoring of slow-moving landslide with L- and C-band SAR interferometry. Remote Sens. Lett. 2014, 5, 951-960. [CrossRef]

18. Bianchini, S.; Ciampalini, A.; Raspini, F.; Bardi, F.; Di Traglia, F.; Moretti, S.; Casagli, N. Multi-temporal evaluation of landslide movements and impacts on buildings in San Fratello (Italy) by means of C-band and X-band PSI data. Pure Appl. Geophys. 2015, 172, 3043-3065. [CrossRef]

19. Haghshenas Haghighi, M.; Motagh, M. Assessment of ground surface displacement in Taihape landslide, New Zealand, with C-and X-band SAR interferometry. N. Z. J. Geol. Geophys. 2016, 59, 136-146. [CrossRef]

20. Liu, C.Z.; Miao, T.B.; Chen, H.Q.; Dong, K.J.; Li, Z.H.; Li, H.J. Basic feature and origin of the "8.8" mountain torrent-debris flow disaster happened in Zhouqu Country, Gansu, China, Aug. 8, 2010. Geol. Bull. China 2011, 30, 141-150. (In Chinese)

21. Yu, B.; Yang, Y.H.; Su, Y.C.; Huang, W.J.; Wang, G.F. Research on the giant debris flow hazards in Zhouqu County, Gansu province on August 7, 2010. J. Eng. Geol. 2010, 18, 437-444. (In Chinese)

22. Bai, S.B.; Wang, J.; Thiebes, B.; Cheng, C.; Yang, W.P. Analysis of the relationship of landslide occurrence with rainfall: A case study of Wudu County, China. Arab. J. Geosci. 2014, 7, 1277-1285. [CrossRef]

23. $\mathrm{Yu}, \mathrm{Z}$.S. Research on the prediction of disaster losses and the mode of causing of Xieliupo landslide. Gansu Sci. Technol. 2007, 23, 72-76. (In Chinese)

24. Li, B. Study on Risk Assessment of Suoertou Landslide in Zhouqu County, Gansu Province. Master's Thesis, China University of Geosciences, Beijing, China, 2012. (In Chinese)

25. Zhang, L.; Lu, Z.; Ding, X.L.; Jung, H.S.; Feng, G.; Lee, C.W. Mapping ground surface deformation using temporarily coherent point SAR interferometry: Application to Los Angeles Basin. Remote Sens. Environ. 2012, 117, 429-439. [CrossRef]

26. Zhang, L.; Ding, X.L.; Lu, Z.; Jung, H.S.; Hu, J.; Feng, G.C. A novel multitemporal InSAR model for joint estimation of deformation rates and orbital errors. IEEE Trans. Geosci. Remote Sens. 2014, 52, 3529-3540. [CrossRef]

27. Liu, G.; Jia, H.; Nie, Y.; Li, T.; Zhang, R.; Yu, B.; Li, Z. Detecting subsidence in coastal areas by ultrashort-baseline TCPInSAR on the time series of high-resolution TerraSAR-X images. IEEE Trans. Geosci. Remote Sens. 2014, 52, 1911-1923.

28. Sun, Q.; Zhang, L.; Ding, X.L.; Hu, J.; Liang, H.Y. Investigation of slow-moving landslides from ALOS/PALSAR images with TCPInSAR: A case study of Oso, USA. Remote Sens. 2014, 7, 72-88. [CrossRef]

29. Dheenathayalan, P.; Small, D.; Schubert, A.; Hanssen, R.F. High-precision positioning of radar scatterers. J. Geod. 2016, 90, 403-422. [CrossRef]

30. Wright, T.J.; Parsons, B.E.; Lu, Z. Toward mapping surface deformation in three dimensions using InSAR. Geophys. Res. Lett. 2004, 31. [CrossRef]

31. Hu, J.; Li, Z.W.; Ding, X.L.; Zhu, J.J.; Zhang, L.; Sun, Q. Resolving three-dimensional surface displacements from InSAR measurements: A review. Earth Sci. Rev. 2014, 133, 1-17. [CrossRef]

32. Hu, J.; Li, Z.W.; Ding, X.L.; Zhu, J.J.; Zhang, L.; Sun, Q. 3D coseismic displacement of 2010 Darfield, New Zealand earthquake estimated from multi-aperture InSAR and D-InSAR measurements. J. Geod. 2012, 86, 1029-1041. [CrossRef]

33. Jung, H.S.; Lu, Z.; Won, J.S.; Poland, M.P.; Miklius, A. Mapping three-dimensional surface deformation by combining multiple-aperture interferometry and conventional interferometry: Application to the June 2007 eruption of Kilauea volcano, Hawaii. IEEE Geosci. Remote Sens. Lett. 2011, 8, 34-38. [CrossRef]

34. Gourmelen, N.; Kim, S.W.; Shepherd, A.; Park, J.W.; Sundal, A.V.; BjÖrnsson, H.; Pálsson, F. Ice velocity determined using conventional and multiple-aperture InSAR. Earth Planet. Sci. Lett. 2011, 307, 156-160. [CrossRef]

35. Joughin, I.R.; Kwok, R.; Fahnestock, M.A. Interferometric estimation of three-dimensional ice-flow using ascending and descending passes. IEEE Trans. Geosci. Remote Sens. 1998, 36, 25-37. [CrossRef]

36. Mukherjee, S.; Joshi, P.K.; Muherjee, S.; Ghosh, A.; Garg, R.D.; Mukhopadhyay, A. Evaluation of vertical accuracy of open source Digital Elevation Model (DEM). Int. J. Appl. Earth Obs. 2013, 21, 205-207. [CrossRef]

37. Zhu, J.J.; Xie, J.; Chen, Y.B. Analysis of inequality constraints influence to adjustment results. Acta Geod. Cart. Sin. 2011, 40, 411-415. (In Chinese)

38. Huang, X.; Yang, W.M.; Zhang, C.S.; Shen, H.F.; Liu, T. Deformation characteristics and formation mechanism of Xieliupo landslide in Zhouqu. J. Geomech. 2013, 19, 178-187. (In Chinese) 
39. Cigna, F.; Bateson, L.B.; Jordan, C.J.; Dashwood, C. Simulating SAR geometric disotortions and predicting Persistent Scatterer densities for ERS-1/2 and ENVISAT C-band SAR and InSAR applications: Nationwide feasibility assessment to monitor the landmass of Great Britain with SAR imagery. Remote Sens. Environ. 2014, 152, 441-466. [CrossRef]

40. Jiang, S.; Wen, B.P.; Zhao, C.; Li, R.D. Creep mechanism analysis of Xieliupo landslide in Zhouqu county of Gansu province. Chin. J. Geol. Hazard Cont. 2013, 24, 1-7. (In Chinese)

41. Jiao, Z.H.; Du, F. Research on the mechanism analysis of sluice channel deformation caused by landslide, Zhouqu, Gansu. Resour. Environ. Eng. 2015, 29, 592-597. (In Chinese)

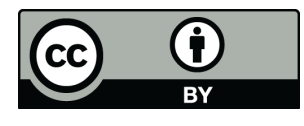

(C) 2016 by the authors; licensee MDPI, Basel, Switzerland. This article is an open access article distributed under the terms and conditions of the Creative Commons Attribution (CC-BY) license (http://creativecommons.org/licenses/by/4.0/). 